\title{
Long-term outcomes of patients receiving drug-eluting stents
}

\author{
Andrew C. Philpott MD, Danielle A. Southern MSc, Fiona M. Clement PhD, P. Diane Galbraith BN MSc, \\ Mouhieddin Traboulsi MD, Merril L. Knudtson MD, William A. Ghali MD, for the APPROACH \\ Investigators
}

Published at www.cmaj.ca on Dec. 18, 2008.

$\infty \infty$

See related commentary by Généreux and Mehran, page 154

\section{ABSTRACT}

Background: We sought to establish the long-term safety of drug-eluting stents compared with bare-metal stents in a usual care setting.

Methods: Using data from a prospective multicentre registry, we compared rates of death and of death or repeat revascularization during 3 years of follow-up of 6440 consecutive patients who underwent angioplasty with either drug-eluting or bare-metal stents between Apr. 1, 2003, and Mar. 31, 2006.

Results: Drug-eluting stents were inserted in 1120 patients and bare-metal stents in 5320. The drug-eluting stents were selected for patients who had a greater burden of comorbid illness, including diabetes mellitus (32.8\% v. $20.8 \%$ in the bare-metal group, $p<0.001)$ and renal disease $(7.4 \%$ v. $5.0 \%, p=0.001)$. At 1 -year follow-up, the drug-eluting stents were associated with a mortality of $3.0 \%$, as compared with $3.7 \%$ with the bare-metal stents (adjusted odds ratio $[\mathrm{OR}] 0.62,95 \%$ confidence interval $[\mathrm{Cl}] 0.46-0.83)$. The rate of the composite outcome of death or repeat revascularization was $12.0 \%$ for the drug-eluting stents and $15.8 \%$ for the bare-metal stents (adjusted OR $0.40,95 \% \mathrm{Cl} 0.33-$ 0.49). In the subgroup of patients who had acute coronary syndromes, the adjusted OR for this composite outcome was $0.46(95 \% \mathrm{Cl} 0.35-0.61)$. During the 3 years of observation, the relative risks for death and repeat revascularization varied over time. In year 1, there was an initial period of lower risk in the group with drug-eluting stents than in the group with bare-metal stents; this was followed by a shift toward outcome rates favouring bare-metal stents in years 2 and 3 . The adjusted relative risk of the composite outcome of death or repeat revascularization associated with drug-eluting stents relative to bare-metal stents was 0.73 early in the first year of follow-up; it then rose gradually over time, to a peak of 2.24 at 3 years.

Interpretation: Drug-eluting stents are safe and effective in the first year following insertion. Thereafter, the possibility of longer term adverse events cannot be ruled out.

Une version française de ce résumé est disponible à l'adresse www.cmaj.ca/cgi/content/full/180/2/167/DC1

CMAJ 2009;180(2):167-74.
$\mathrm{D}$ rug-eluting stents now comprise at least $85 \%$ of stents used in the United States and up to $40 \%$ or more of stents elsewhere. The overwhelming worldwide use of drug-eluting stents has, however, been tempered by the cost differential to bare-metal stents, the lack of data on long-term outcomes in large patient populations and, more recently, emerging concerns about safety because of reports of late thrombosis. ${ }^{1-8}$

The use of stents has been shown to reduce the rates of repeat revascularization and restenosis after angioplasty compared with angioplasty alone. ${ }^{9}$ Despite this, the long-term efficacy of stent use has been limited by the need for repeat revascularization owing to restenosis. ${ }^{10}$ Drug-eluting stents were developed to address this problem. Both clinical trials $^{11-20}$ and registry data ${ }^{21-25}$ have shown reduced rates of restenosis with drug-eluting stents up to 4 years after implantation. This advantage appears to extend to patients with acute coronary syndromes: a recent 2-year follow-up study involving 7217 patients with acute coronary syndromes suggested that rates of death were lower among patients with drugeluting stents than among those with bare-metal stents. ${ }^{26}$

The possibility of late thrombosis associated with drug-eluting stents is, however, a concern. Rates of late thrombosis have been reported to be 3.6-5.9 events per 1000 patients receiving drug-eluting stents. ${ }^{27}$ This adverse event has been the subject of a review by the US Food and Drug Administration and has captured the attention of authoritative bodies around the world.

Because of concerns about the long-term safety of drugeluting stents, we compared the rates of death and of death or repeat revascularization over 3 years among patients who received either bare-metal or drug-eluting stents during angioplasty.

\section{Methods}

\section{Study design and patient population}

We assembled a prospective cohort of all patients undergoing percutaneous coronary intervention with either bare-metal or

From the Department of Medicine (Philpott, Galbraith, Traboulsi, Knudtson, Ghali) and the Department of Community Health Sciences, Centre for Health and Policy Studies (Southern, Clement, Ghali), University of Calgary, Calgary, Alta. 
drug-eluting stents between Apr. 1, 2003, and Mar. 31, 2006. Patients were followed up to Mar. 31, 2007. We chose the date of Apr. 1, 2003, to coincide with the date that drugeluting stents were approved for use in Canada.

The Alberta Provincial Project for Outcome Assessment in Coronary Heart Disease (APPROACH) is an initiative for a prospective, geographically defined clinical registry that captures detailed clinical information on all patients undergoing catheterization in the province of Alberta (population about 3 million). Data collection for the registry began in 1995 , with patients followed longitudinally for assessment of clinical, health-related quality-of-life and economic outcomes. ${ }^{28}$ Validation and enhancement of data are performed with the use of a validated methodology..$^{29,30}$

For our study, we recorded the following clinical variables at the time of catheterization: patient age and sex, presence of congestive heart failure, peripheral vascular disease, cerebrovascular disease, chronic pulmonary disease, renal disease (as indicated by elevated serum creatinine level), diabetes mellitus, dialysis status, hyperlipidemia, hypertension, liver or gastrointestinal disease, malignant disease, smoking status (categorized as "never," "former" or "current"), prior myocardial infarction (anytime), prior coronary artery bypass graft surgery, prior percutaneous coronary intervention and use of glycoprotein IIb/IIIa inhibitors. In addition, we recorded the primary indication for catheterization as acute coronary syndrome (myocardial infarction within 8 weeks before catheterization or unstable angina), non-acute coronary syndrome (stable angina) or "other."

We recorded the extent of coronary disease and derived the weighted Duke Index and Duke Myocardial Jeopardy score, an estimate of the percentage of myocardium at risk given the extent of coronary disease. ${ }^{31}$ We graded left ventricular ejection fraction into 5 categories: less than 20\%, 20\%$34 \%$, 35\%-50\%, more than 50\% and "ventriculogram not done." We recorded details of the percutaneous coronary intervention, including use of stent, type of stent (drug-eluting or bare metal), length of stent and number of stents.

\section{Outcomes}

We determined the occurrence of death through a semiannual linkage to data from the Alberta Bureau of Vital Statistics. We obtained information on subsequent revascularization (percutaneous coronary intervention or coronary artery bypass graft surgery) from the APPROACH database. For the purposes of this paper, we chose all-cause mortality and a composite outcome of death or repeat revascularization as the outcomes of interest.

\section{Statistical analysis}

We used the $\chi^{2}$ test to compare the clinical and demographic characteristics of patients who received drug-eluting stents with those of patients who received bare-metal stents. We analyzed outcomes at 1 year because we had follow-up data for all patients to at least 1 year. We used logistic regression analysis to calculate risk-adjusted odds ratios (ORs) for death and the composite outcome of death or repeat revascularization at 30 days and at 1 year. ORs below 1.0 indicate a de- creased risk of events among patients who received drugeluting stents.

For survival beyond 1 year, we used Kaplan-Meier survival analyses to compare crude survival and rates of the composite outcome of death or repeat revascularization over the 3-year follow-up period. The survival analyses accounted for censoring of patients when follow-up ended without an event. Next, we extended our survival analysis to include a spline analysis - an analytical technique that dynamically determines the relative risk at moments in time - both in unadjusted and risk-adjusted forms for the 3 years of follow-up. Comprehensive risk adjustment was conducted to account for all of the baseline clinical risk variables presented in Table 1. Spline analysis is a graphical technique that plots the relative risk associated with drug-eluting stents relative to bare-metal stents against time using Schoenfeld residuals. ${ }^{32,33}$ The resulting curves show the change in relative risk over time, with $95 \%$ confidence intervals.

For a sensitivity analysis, we used propensity scores to compare the outcomes of patients in the 2 stent groups. The likelihood (or propensity) to receive drug-eluting stents was modelled, and we then compared outcomes of the 2 groups across tertiles of likelihood to receive drug-eluting stents. We extended the propensity analysis to conduct a 1-to-1 match of each patient with drug-eluting stents to a single patient with bare-metal stents, matched by their propensity to receive drug-eluting stents.

\section{Results}

A total of 6471 patients underwent percutaneous coronary intervention with stenting. Of these patients, $1120(17.3 \%)$ received drug-eluting stents, and 5320 (82.2\%) received bare-metal stents. Another 31 patients had undeployed stents and were excluded from further analysis. Patients with drug-eluting stents were more likely than those with bare-metal stents to be female and to have a higher rate of renal disease, diabetes mellitus, hyperlipidemia and hypertension (Table 1).

Complete follow-up data for all patients to at least the end of year 1 allowed us to estimate all event rates precisely at 30 days, 6 months and 1 year (Table 2). The 30-day mortality was significantly lower among patients who received drugeluting stents than among those with bare-metal stents $(0.7 \%$ v. $1.8 \%$, risk-adjusted odds ratio [OR] $0.50,95 \%$ confidence interval $[\mathrm{CI}] 0.33-0.76)$. This difference persisted to the end of year $1(3.0 \%$ v. $3.7 \%$, risk-adjusted OR $0.62,95 \% \mathrm{CI}$ $0.46-0.83)$. The rate of the composite outcome of death or repeat revascularization was significantly lower in the drugeluting stent group than in the bare-metal stent group at 30 days and at the end of year $1(4.1 \%$ v. $6.3 \%$, adjusted OR $0.42,95 \%$ CI $0.31-0.57$ at 30 days; $12.0 \%$ v. $15.8 \%$, adjusted OR $0.40,95 \%$ CI $0.33-0.49$ at 1 year). We noted the same general findings among patients with acute coronary syndromes. Among patients with non-acute coronary syndromes (i.e., stable angina), we did not detect statistically significant differences in either mortality or the composite outcome at any point between the 2 stent groups. 
Table 1: Characteristics of patients who underwent coronary angioplasty, by type of stent received

\begin{tabular}{|c|c|c|c|}
\hline \multirow[b]{2}{*}{ Characteristic } & \multicolumn{2}{|c|}{ Type of stent; no. (\%) of patients* } & \multirow[b]{2}{*}{$p$ value } \\
\hline & $\begin{array}{c}\text { Bare metal } \\
n=5320\end{array}$ & $\begin{array}{l}\text { Drug-eluting } \\
n=1120\end{array}$ & \\
\hline Age, yr, mean (SD) & $62.5(11.9)$ & $62.3(11.6)$ & 0.6 \\
\hline Sex, male & $4022(75.6)$ & 799 (71.3) & 0.002 \\
\hline Congestive heart failure & $527 \quad(9.9)$ & $91 \quad(8.1)$ & 0.06 \\
\hline Peripheral vascular disease & $319 \quad(6.0)$ & $69(6.2)$ & 0.81 \\
\hline Cerebrovascular disease & $298 \quad(5.6)$ & $76 \quad(6.8)$ & 0.14 \\
\hline Chronic pulmonary disease & $761(14.3)$ & $147(13.1)$ & 0.31 \\
\hline Renal diseaset & $266 \quad(5.0)$ & $83(7.4)$ & 0.001 \\
\hline Diabetes mellitus & $1106(20.8)$ & $367(32.8)$ & $<0.001$ \\
\hline Dialysis & $48 \quad(0.9)$ & $19(1.7)$ & 0.02 \\
\hline Hyperlipidemia & $4298(80.8)$ & $983(87.8)$ & $<0.001$ \\
\hline Hypertension & $3532(66.4)$ & 791 (70.6) & 0.006 \\
\hline Liver or gastrointestinal disease & $404 \quad(7.6)$ & 99 (8.8) & 0.19 \\
\hline Malignant disease & $207 \quad(3.9)$ & $41 \quad(3.7)$ & 0.72 \\
\hline Current smoker & $1899(35.7)$ & $277(24.7)$ & $<0.001$ \\
\hline Former smoker & 1665 (31.3) & $416(37.1)$ & $<0.001$ \\
\hline Prior myocardial infarction & $3059(57.5)$ & $510(45.5)$ & $<0.001$ \\
\hline Prior coronary artery byass graft surgery & $303 \quad(5.7)$ & $132(11.8)$ & $<0.001$ \\
\hline Prior percutaneous coronary intervention & $197 \quad(3.7)$ & $60 \quad(5.4)$ & 0.01 \\
\hline Use of glycoprotein IIb/IIla inhibitors & $2777(52.2)$ & $627(56.0)$ & 0.02 \\
\hline \multicolumn{4}{|l|}{ Primary indication for angioplasty } \\
\hline Acute coronary syndrome & $4460(83.8)$ & $726(64.8)$ & $<0.001$ \\
\hline Non-acute coronary syndrome & $848(15.9)$ & $387(34.6)$ & $<0.001$ \\
\hline Other & $12(0.2)$ & $7 \quad(0.6)$ & $<0.001$ \\
\hline Length of stent, mm, mean (SD) & $16.6(6.1)$ & $17.7(7.7)$ & $<0.001$ \\
\hline Diameter of stent, mm, mean (SD) & $3.6 \quad(1.4)$ & $3.3(1.3)$ & $<0.001$ \\
\hline Duke Myocardial Jeopardy score, $¥$ mean (SD) & $42.4(22.6)$ & $50.5(23.1)$ & $<0.001$ \\
\hline \multicolumn{4}{|l|}{ Ejection fraction } \\
\hline$>50$ & $3155(59.3)$ & $665(59.4)$ & 0.03 \\
\hline $35-50$ & $1239(23.3)$ & $219(19.6)$ & 0.03 \\
\hline 20-34 & $197 \quad(3.7)$ & $47(4.2)$ & 0.03 \\
\hline$<20$ & $37 \quad(0.7)$ & $9(0.8)$ & 0.03 \\
\hline Ventriculogram not done & $692(13.0)$ & $180(16.1)$ & \\
\hline \multicolumn{4}{|l|}{ Anatomy§ } \\
\hline Low risk & $3400(63.9)$ & $604(53.9)$ & 0.01 \\
\hline High risk & $1617(30.4)$ & $431(38.5)$ & 0.01 \\
\hline Left main & $117 \quad(2.2)$ & $57(5.1)$ & 0.01 \\
\hline Data missing & $186 \quad(3.5)$ & $28(2.5)$ & \\
\hline No. of stents, mean (SD) & $1.75 \quad(1.02)$ & $1.46 \quad(0.77)$ & $<0.001$ \\
\hline No. of stents & & & $<0.001$ \\
\hline 1 & $2793(52.5)$ & $750(67.0)$ & \\
\hline 2 & 1612 (30.3) & $263(23.5)$ & \\
\hline 3 & $557(10.5)$ & $80 \quad(7.1)$ & \\
\hline 4 & $248 \quad(4.7)$ & 19 (1.7) & \\
\hline$\geq 5$ & $110 \quad(2.1)$ & $8 \quad(0.7)$ & \\
\hline
\end{tabular}

*Unless stated otherwise.

†As indicated by elevated serum creatinine level.

¥An estimate of the percentage of myocardium at risk given the extent of coronary artery disease.

$\S$ High risk includes 3-vessel disease, or 2-vessel disease with disease of the proximal left anterior descending artery; low risk includes other 2-vessel disease, 1-vessel disease, lesions with $<50 \%$ stenosis and normal anatomy. 
Figure 1 presents the Kaplan-Meier survival curves over the 3 years of follow-up. The survival curves for patients with acute coronary syndromes and for those with non-acute coronary syndromes were similar to the survival curves for the overall study population. When we examined overall event-free survival for the combined outcome (i.e., no death or repeat revascularization), we observed a similar pattern (Figure 2). There were only small differences in survival at year $3(79.4 \%$ v. $78.5 \%, p=$ 0.15 ). The subgroup of patients with acute coronary syndromes had the same general pattern of survival (Figure 2, middle panel). In the subgroup with non-acute coronary syndromes, the differences in event-free survival between the 2 stent groups over time were not significant (Figure 2, bottom panel).

Our stratified analysis of propensity scores revealed that the 1 -year mortality was better among patients with drug-eluting stents than among those with bare-metal stents in the 2 tertiles of higher propensity to receive drug-eluting stents (Appendix 1, available at www.cmaj.ca/cgi/content/full/180/2/167/DC2). In the extended propensity analysis in which we conducted a 1-to-1 match of each patient with drug-eluting stents to a single patient with bare-metal stents, we found that survival was again better for patients with drug-eluting stents than for those with bare-metal stents $(2.7 \%$ v. $4.3 \%$ for death, $p=0.043$; $11.7 \%$ v. $12.7 \%$ for the combined outcome of death or repeat revascularization, $p=0.46$ ) (Appendix 1).

\section{Time-dependent spline analysis}

In our time-dependent spline analysis, we observed an initial survival benefit with drug-eluting stents (Figure 3, top panel). Over time the effect diminished, with the relative risk

Table 2: Outcomes in the first year after stent insertion, by type of stent

\begin{tabular}{|c|c|c|c|c|c|}
\hline \multirow[b]{2}{*}{ Outcome } & \multicolumn{2}{|c|}{$\begin{array}{l}\text { Type of stent; } \\
\text { no. (\%) of patients }\end{array}$} & \multirow[b]{2}{*}{$p$ value } & \multicolumn{2}{|c|}{ Odds ratio (95\% confidence interval) } \\
\hline & Bare metal & Drug-eluting & & Crude* & Adjusted $\dagger$ \\
\hline All patients & $n=5320$ & $n=1120$ & & & \\
\hline \multicolumn{6}{|l|}{ Death } \\
\hline 30 days & $96(1.8)$ & $8 \quad(0.7)$ & 0.008 & $0.50(0.33-0.76)$ & $0.40(0.25-0.64)$ \\
\hline 6 months & 151 & $21(1.9)$ & 0.07 & $0.62(0.45-0.85)$ & $0.53(0.37-0.75)$ \\
\hline 1 year & $195(3.7)$ & $33(3.0)$ & 0.24 & $0.74(0.57-0.96)$ & $0.62(0.46-0.83)$ \\
\hline \multicolumn{6}{|l|}{ Composite outcome $\neq$} \\
\hline 30 days & $335(6.3)$ & $46(4.1)$ & 0.004 & $0.44(0.33-0.58)$ & $0.42(0.31-0.57)$ \\
\hline 6 months & $665(12.5)$ & $100(8.9)$ & 0.007 & $0.44(0.36-0.53)$ & $0.38(0.30-0.48)$ \\
\hline 1 year & $841(15.8)$ & $134(12.0)$ & 0.001 & $0.47(0.40-0.56)$ & $0.40(0.33-0.49)$ \\
\hline $\begin{array}{l}\text { Patients with acute coronary } \\
\text { syndromes }\end{array}$ & $n=4195$ & $n=669$ & & & \\
\hline \multicolumn{6}{|l|}{ Death } \\
\hline 30 days & $84(2.0)$ & $6(0.9)$ & 0.05 & $0.60(0.35-1.03)$ & $0.46(0.25-0.87)$ \\
\hline 6 months & 130 & $16(2.4)$ & 0.33 & $0.78(0.53-1.17)$ & $0.59(0.36-0.94)$ \\
\hline 1 year & $168(4.0)$ & $24(3.6)$ & 0.61 & $0.88(0.63-1.23)$ & $0.68(0.46-1.01)$ \\
\hline \multicolumn{6}{|l|}{ Composite outcome $\neq$} \\
\hline 30 days & $298(7.1)$ & $34(5.1)$ & 0.05 & $0.58(0.41-0.81)$ & $0.55(0.37-0.80)$ \\
\hline 6 months & $558(13.3)$ & $62 \quad(9.3)$ & 0.004 & $0.54(0.42,0.70)$ & $0.45(0.33-0.61)$ \\
\hline 1 year & $696(16.6)$ & 79 (11.8) & 0.002 & $0.56(0.45-0.70)$ & $0.46(0.35-0.61)$ \\
\hline $\begin{array}{l}\text { Patients with non-acute } \\
\text { coronary syndromes }\end{array}$ & $n=1125$ & $n=451$ & & & \\
\hline \multicolumn{6}{|l|}{ Death } \\
\hline 30 days & $12(1.1)$ & $2(0.4)$ & 0.23 & $0.61(0.30-1.28)$ & $0.49(0.22-1.11)$ \\
\hline 6 months & $23(2.0)$ & $5(1.1)$ & 0.24 & $0.61(0.36-1.04)$ & $0.56(0.31-1.01)$ \\
\hline 1 year & $27 \quad(2.4)$ & $9(2.0)$ & 0.63 & $0.82(0.53-1.27)$ & $0.69(0.42-1.13)$ \\
\hline \multicolumn{6}{|l|}{ Composite outcome } \\
\hline 30 days & $39(3.5)$ & $12(2.7)$ & 0.41 & $0.55(0.32-0.95)$ & $0.52(0.29-0.93)$ \\
\hline 6 months & $111 \quad(9.9)$ & 38 (8.4) & 0.38 & $0.47(0.34-0.66)$ & $0.46(0.32-0.67)$ \\
\hline 1 year & $146(13.0)$ & $55(12.2)$ & 0.67 & $0.53(0.40-0.71)$ & $0.49(0.35-0.67)$ \\
\hline
\end{tabular}

*Baseline group is drug-eluting stents.

†Adjusted for age, sex, comorbidities, indication, use of glycoprotein Ilb/Illa inhibitors, mean length and diameter of stent, ejection fraction, coronary anatomy and Duke Myocardial Jeopardy score.

$\ddagger D$ Death or repeat revascularization (percutaneous coronary intervention or coronary artery bypass graft surgery). 
crossing 1.0 and indicating better survival with the bare-metal stents.

The corresponding analysis for the combined outcome of death or repeat revascularization showed a similar pattern (Figure 3, bottom panel). During the initial period, outcomes were better with the drug-eluting stents than with the baremetal stents. Over time, the effect shifted, with the relative risk for the combined outcome favouring bare-metal stents from about 240 days onward. The descriptive statements presented here for Figure 3 emphasize the point estimates for the relative risks at individual moments in time, without attention to statistical significance at each moment. The figure does, however, present bands for the $95 \%$ confidence intervals to inform judgments of statistical significance over time.

After we adjusted the spline analysis for baseline risk factors, we found that the findings were similar to those of the unadjusted analysis (Figure 4). Again, there was an initial pattern of decreased risk of events with the drug-eluting stents, followed by a gradual transition over time toward better outcomes with the bare-metal stents. The adjusted relative risk of the composite outcome of death or repeat revascularization associated with drug-eluting stents relative to baremetal stents was 0.73 early in the first year of follow-up; it then rose gradually over time, to a peak of 2.24 at 3 years.

\section{Interpretation}

Our study showed that patients who received drug-eluting stents during percutaneous coronary interventions had improved survival and lower rates of repeat revascularization in the first year of follow-up compared with patients who received bare-metal stents. However, our time-dependent spline analysis extending to 3 years showed an increased risk of death and repeat revascularization over time associated with the drug-eluting stents relative to the bare-metal stents.

The early studies of the efficacy of drugeluting stents focused on outcomes in the shorter term, and in some cases restenosis of target vessels as the primary outcome..$^{11,12,34}$ Our findings build on the results of more recent studies, some of which included patients in usual-care settings or had longer follow-up, or both. ${ }^{5,21,23-26,35}$

Despite recent concerns about the safety of drug-eluting stents, we did not detect an overwhelming increase in the risk of death among patients who received this type of stent. Also, we did not observe any notable survival drops or clusters of deaths, particularly when the survival of patients with drug-eluting stents was juxtaposed with that of patients with bare-metal stents.

\section{All patients}

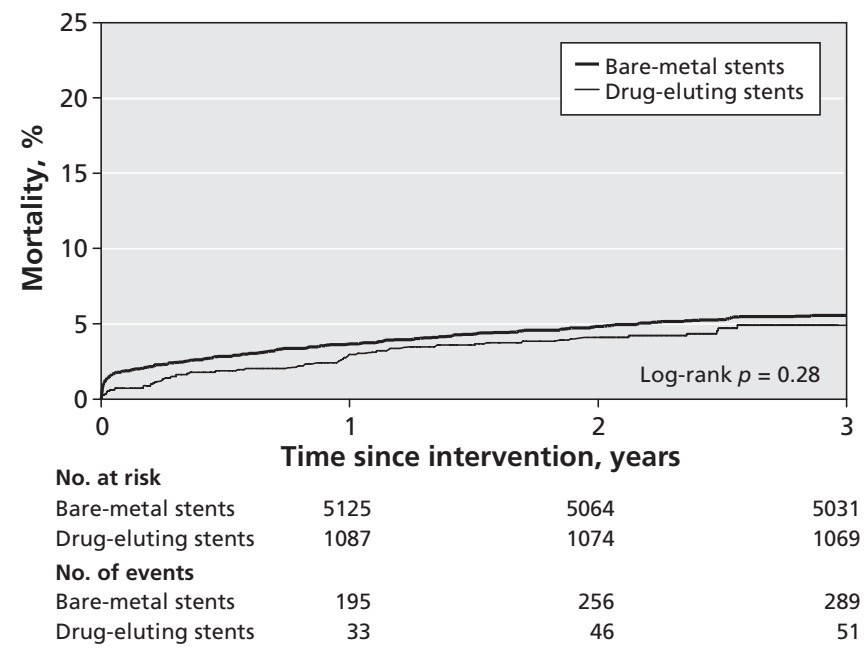

Patients with acute coronary syndromes

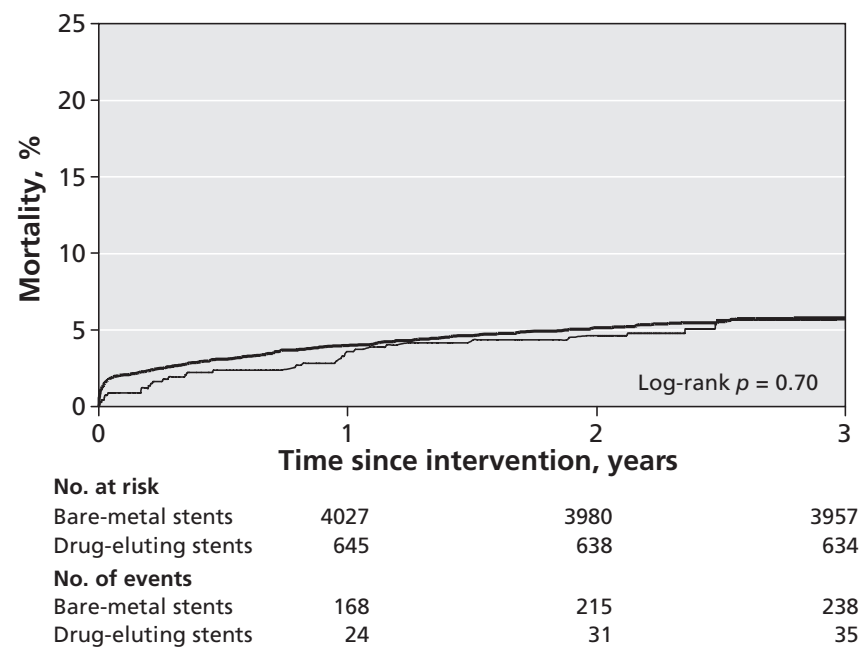

Patients with non-acute coronary syndromes

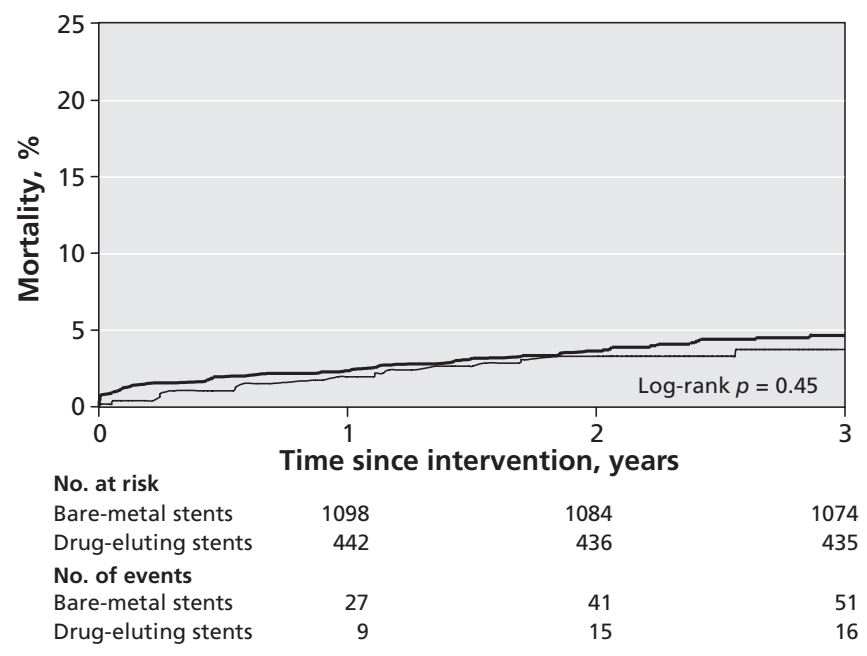

Figure 1: Unadjusted time to death among patients with bare-metal stents and those with drug-eluting stents. Top panel: all patients $(n=6440)$; middle panel: patients with acute coronary syndromes $(n=4864)$; bottom panel: patients with non-acute coronary syndromes $(n=1576)$. 


\section{All patients}

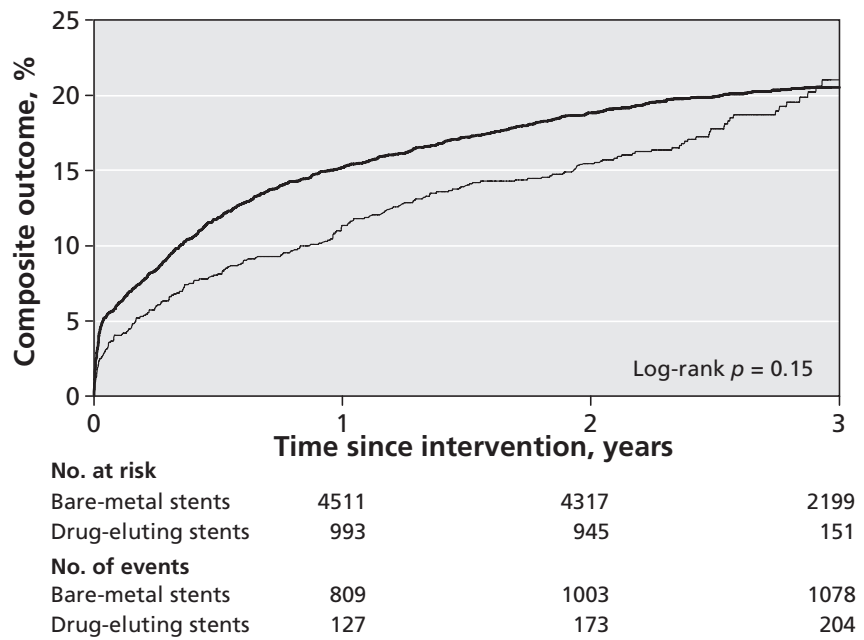

Patients with acute coronary syndromes

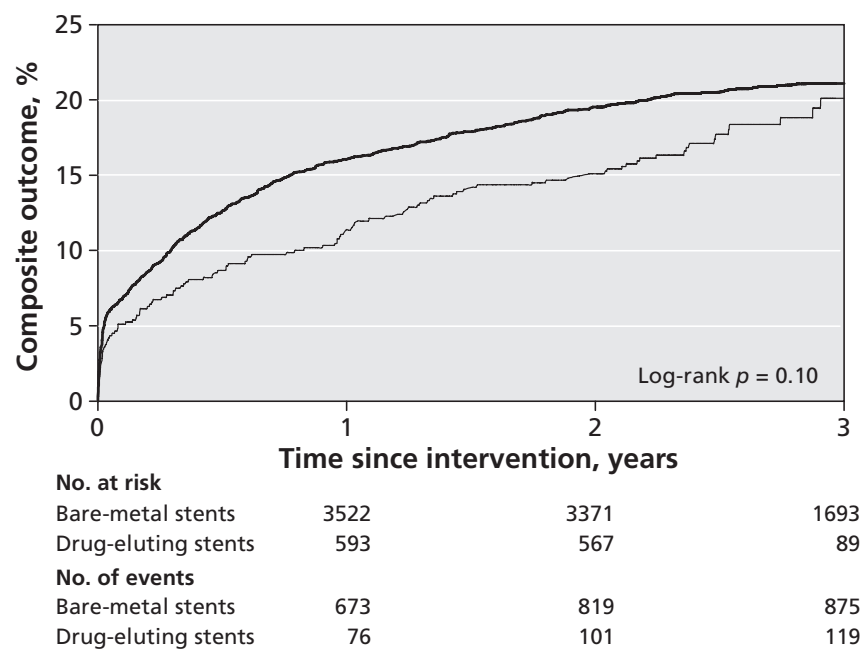

Patients with non-acute coronary syndromes

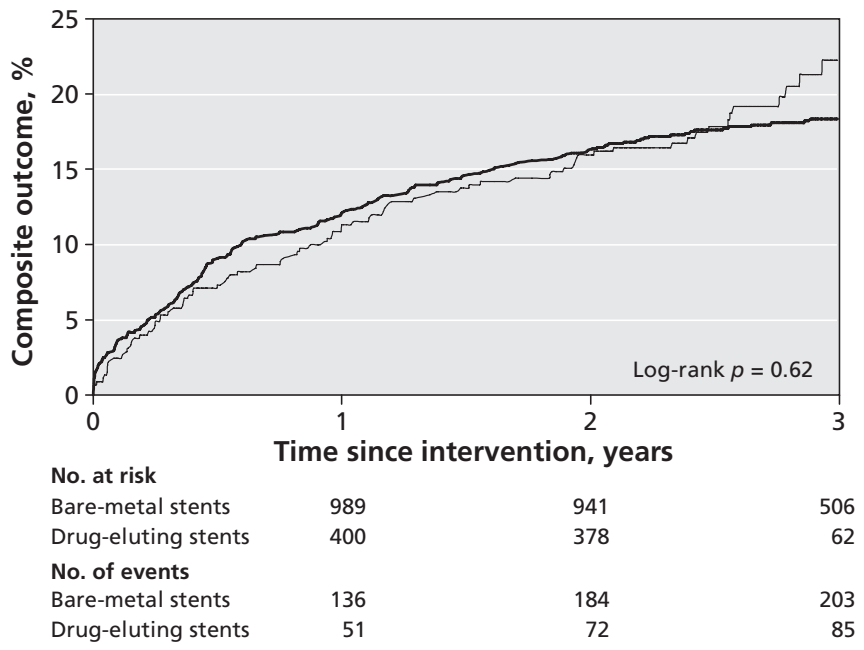

Figure 2: Unadjusted time to composite outcome (death or repeat revascularization) among patients with bare-metal stents and those with drug-eluting stents. Top panel: all patients $(n=6440)$; middle panel: patients with acute coronary syndromes ( $n=4864)$; bottom panel: patients with non-acute coronary syndromes $(n=1576)$.
Patients who received drug-eluting stents in our study had different baseline characteristics than those who received bare-metal stents. Drugeluting stents appeared to be used in an appropriate manner, specifically when the risk of restenosis was known to be increased (i.e., in longer lesions, in smaller vessels, and in patients with diabetes). In the early years of our study, there appeared to be a relative aversion to the use of drugeluting stents in patients with acute coronary syndromes. At the time, this clinical situation lacked the support of data from recently published randomized controlled trials supporting the use of drug-eluting stents in patients with ST-segment elevation myocardial infarction. ${ }^{36,37}$

The focus of our study - the long-term survival of patients with drug-eluting stents - enables inferences on the long-term safety profile of stents in light of the recent concerns about drugeluting stents. Our comparison of the 2 types of stents was not a randomized controlled trial. Therefore, because of potential selection bias and unmeasured risks, we caution readers not to interpret our study as an efficacy analysis.

Despite these limitations, we did perform a risk-adjusted time-dependent outcome analysis to assess the relative risk of adverse events associated with drug-eluting stents relative to baremetal stents. Interestingly, our findings suggest that the pace of occurrence of adverse events among patients who received drug-eluting stents was not uniform. In fact, there may have been a slight acceleration of events at about 1 year after the percutaneous coronary intervention, in both the unadjusted and risk-adjusted analyses. The potential pathophysiologic factors underlying this observation are not clear. The typical pattern of stopping thiopyridine therapy between 6 months and 1 year after stent placement may be a contributing factor. ${ }^{38}$ Despite the possible acceleration of adverse events at about 1 year, however, the overall survival of patients with drug-eluting stents remained favourable relative to that of patients with bare-metal stents, at least over 3 years of follow-up.

\section{Strengths and limitations}

Our study provides new insights into the longterm safety profile of drug-eluting stents. Indeed, data on the long-term follow-up of patients after stent placement are limited outside of clinical trials. Aside from the studies by Lagerqvist and colleagues ${ }^{23}$ and Marzocchi and colleagues, ${ }^{35}$ the principal reports in this area have described populations with exclusive ${ }^{11}$ or near exclusive ${ }^{22}$ use of drug-eluting stents with comparison to historical controls. We provide a description of the longterm safety of drug-eluting stents compared with 
Death

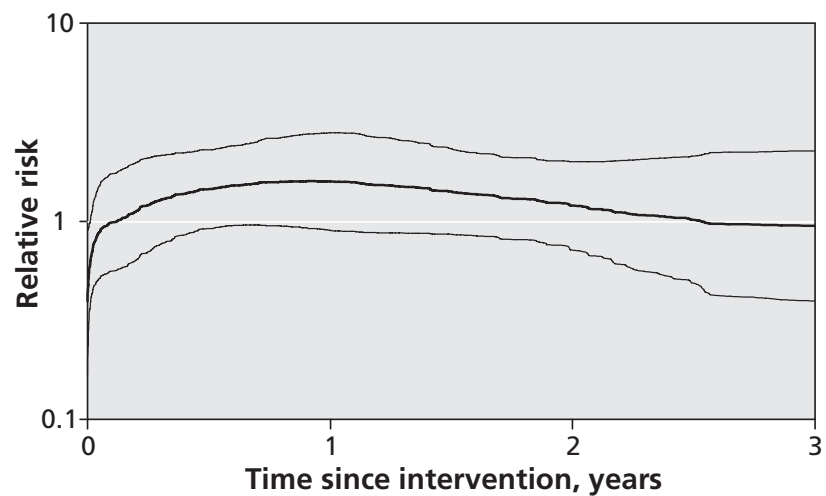

Death or revascularization

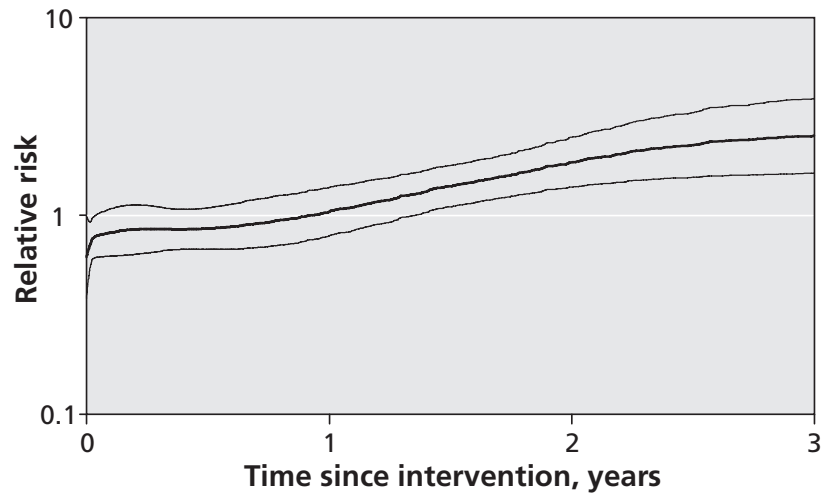

Figure 3: Unadjusted spline analysis of the relative risk of death (top panel) and the composite outcome of death or repeat revascularization (bottom panel) among patients with drugeluting stents ( $v$. those with bare-metal stents) over the 3-year follow-up period. A relative risk below 1.0 indicates a decreased risk of events among patients with drug-eluting stents. The thin lines above and below the thicker line represent $95 \%$ confidence intervals.

bare-metal stents. Furthermore, our data showed interesting differences in the outcomes between patients with stable angina and those with acute coronary syndromes.

Our study has limitations. Because of the lack of data on long-term medication use, we can only speculate on the potential role the discontinuation of antiplatelet therapy had on the later onset of adverse outcomes in patients with drug-eluting stents. Furthermore, despite a reasonably large sample, our statistical power was not sufficient to comment on small differences in adverse events between the stent groups in the longer term. Also, we confined our analysis of outcomes to death and clinically driven repeat revascularization. However, many patients who experience myocardial infarction following stent insertion would undergo subsequent repeat catheterization, and some may also die. An additional caveat is that, although we performed a careful risk-adjustment analysis, our findings may relate to unmeasured confounding clinical factors, rather than to the type of stent used.$^{39}$ Finally, because our composite outcome included repeat revascularization, we probably captured procedures done because of disease progression rather than

\section{Death}

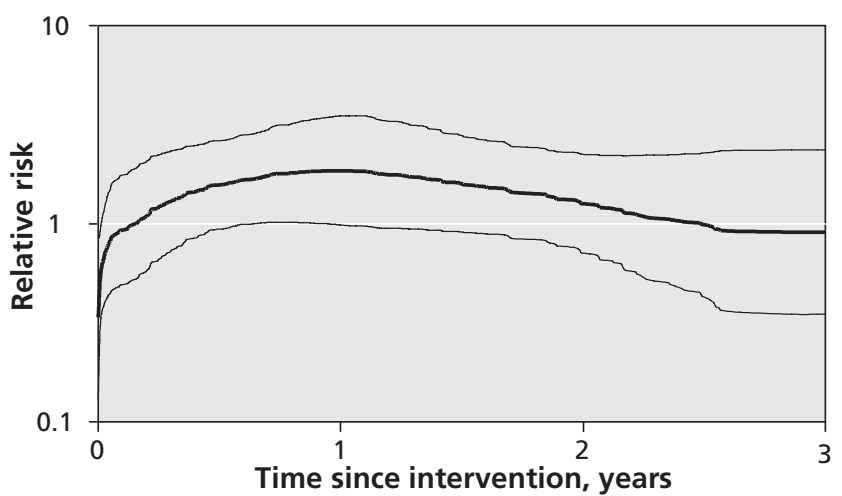

\section{Death or revascularization}

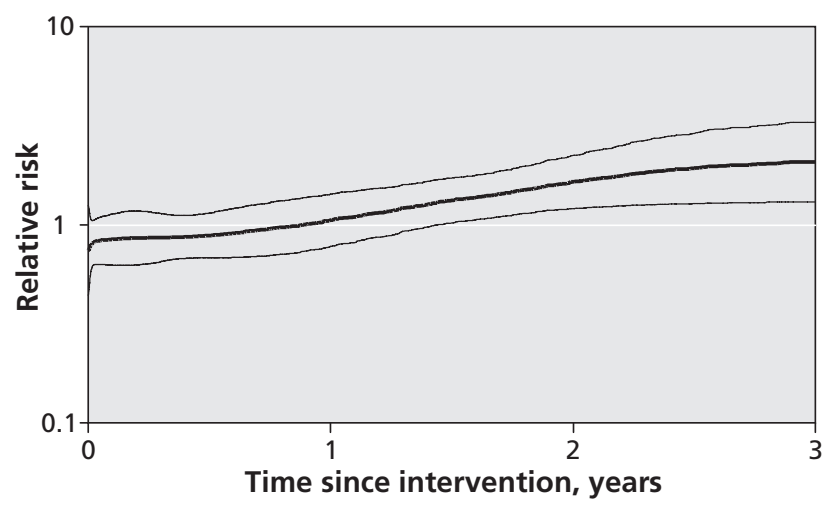

Figure 4: Risk-adjusted spline analysis of the relative risk of death (top panel) and the composite outcome of death or repeat revascularization (bottom panel) among patients with drug-eluting stents ( $v$. those with bare-metal stents) over the 3year follow-up period. A relative risk below 1.0 indicates a decreased risk of events among patients with drug-eluting stents. The thin lines above and below the thicker line represent $95 \%$ confidence intervals.

restenosis. However, this limitation probably did not significantly affect our analysis of the composite outcome, because disease progression was likely similar in the 2 stent groups.

\section{Conclusions}

Our study findings suggest that the long-term survival (to 3 years) of patients with drug-eluting stents remains favourable overall. It is not measurably worse than that of patients with bare-metal stents. Further work, however, is needed to characterize better the possibly dynamic risk profile of drug-eluting stents over time. Also, data are needed on the potential value of long-term dual antiplatelet therapy to protect against late adverse events in patients with drug-eluting stents.

This article has been peer reviewed.

Competing interests: Merril Knudtson received fees from Medtronics for chairing an interventional workshop during the 2006 and 2007 Canadian Cardiovascular Society meetings. None declared for Andrew Philpott, Danielle Southern, Fiona Clement, Diane Galbraith, Mouhieddin Traboulsi or William Ghali. 
Contributors: Andrew Philpott developed the study concept and design, compiled background literature and drafted the manuscript. Danielle Southern and Fiona Clement conducted the data analyses. Diane Galbraith oversaw the collection of data from the APPROACH database. Mouhieddin Traboulsi contributed to the study design and literature search. Merril Knudtson is the principal investigator of APPROACH; he contributed to the study design and literature search. William Ghali oversaw and contributed to all aspects of the study, from conception and design, to analysis, to completion of the final manuscript for publication. All of the authors critically revised the manuscript for important intellectual content and approved the final version submitted for publication.

Acknowledgements: We appreciate the support from the Calgary Health Region, Capital Health Authority, the Libin Cardiovascular Institute and the Mazankowski Heart Institute. We gratefully acknowledge personnel at the cardiac catheterization laboratories of the Foothills Medical Centre, the Royal Alexandra Hospital and the University of Alberta Hospital for their diligence in collecting and entering data.

Merril Knudtson receives partial support from the Libin Trust Fund. William Ghali is supported by a Government of Canada Research Chair in Health Services Research and by a Senior Health Scholar Award from the Alberta Heritage Foundation for Medical Research.

Funding: APPROACH was initially funded with a grant from the W. Garfield Weston Foundation. The ongoing operation of this project has been made possible through funding from the Canadian Cardiovascular Outcomes Research Team (CCORT [www.ccort.ca]), a Canadian Institutes of Health (CIHR)-funded team grant initiative. APPROACH is also supported by the Province Wide Services Committee of Alberta Health and Wellness and the following industry sponsors: Merck Frosst Canada Inc., Roche Canada, Eli Lilly Canada Inc., Bristol-Myers Squibb, Philips Medical Systems Canada, Searle Pharmaceuticals, Boston Scientific Ltd. and Cordis - a Johnson \& Johnson Company.

\section{REFERENCES}

1. Feres F, Costa JR Jr, Abizaid A. Very late thrombosis after drug-eluting stents. Catheter Cardiovasc Interv 2006;68:83-8.

2. Ishikawa T, Mutoh M, Fuda Y, et al. Documented subacute stent thrombosis within thirty days after stenting with sirolimus-eluting stent (Cypher) for acute myocardial infarction: a Japanese single center retrospective non-randomized study. Circ J 2006;70:1091-2.

3. Joner M, Finn AV, Farb A, et al. Pathology of drug-eluting stents in humans: delayed healing and late thrombotic risk. J Am Coll Cardiol 2006;48:193-202.

4. Manjappa N, Agarwal A, Cavusoglu E. Very late bare-metal stent thrombosis. A case report and review of the literature. J Invasive Cardiol 2006;18:E203-6.

5. Ong AT, McFadden EP, Regar E, et al. Late angiographic stent thrombosis (LAST) events with drug-eluting stents. J Am Coll Cardiol 2005;45:2088-92.

6. Pasceri V, Pelliccia F, Cianfrocca C, et al. Very late thrombosis after sirolimuseluting stent implantation. J Cardiovasc Med (Hagerstown) 2006;7:438-42.

7. Spertus JA, Kettelkamp R, Vance C, et al. Prevalence, predictors, and outcomes of premature discontinuation of thienopyridine therapy after drug-eluting stent placement: results from the PREMIER registry. Circulation 2006;113:2803-9.

8. Virmani R, Guagliumi G, Farb A, et al. Localized hypersensitivity and late coronary thrombosis secondary to a sirolimus-eluting stent: Should we be cautious? Circulation 2004;109:701-5.

9. Brophy JM, Belisle P, Joseph L. Evidence for use of coronary stents. A hierarchical Bayesian meta-analysis. Ann Intern Med 2003;138:777-86.

10. Serruys PW, Kutryk MJB, Ong ATL. Coronary artery stents. N Engl J Med 2006; 354:483-95

11. Morice MC, Serruys PW, Sousa JE, et al. A randomized comparison of a sirolimus-eluting stent with a standard stent for coronary revascularization. $N \mathrm{Engl}$ I Med 2002:346:1773-80.

12. Moses JW, Leon MB, Popma JJ, et al. Sirolimus-eluting stents versus standard stents in patients with stenosis in a native coronary artery. N Engl J Med 2003;349:1315-23.

13. Grube E, Silber S, Hauptmann KE, et al. TAXUS I: six- and twelve-month results from a randomized, double-blind trial on a slow-release paclitaxel-eluting stent for de novo coronary lesions. Circulation 2003;107:38-42.

14. Colombo A, Drzewiecki J, Banning A, et al. Randomized study to assess the effectiveness of slow- and moderate-release polymer-based paclitaxel-eluting stents for coronary artery lesions. Circulation 2003;108:788-94.

15. Schofer J, Schluter M, Gershlick AH, et al. Sirolimus-eluting stents for treatment of patients with long atherosclerotic lesions in small coronary arteries: doubleblind, randomized controlled trial (E-SIRIUS). Lancet 2003;362:1093-9.

16. Schampaert E, Cohen EA, Schluter M, et al. The Canadian study of the sirolimuseluting stent in the treatment of patients with long de novo lesions in small native coronary arteries (C-SIRIUS). J Am Coll Cardiol 2004;43:1110-5.
17. Gershlick A, De Scheerder I, Chevalier B, et al. Inhibition of restenosis with a paclitaxel-eluting, polymer-free coronary stent: the European evaLUation of pacliTaxel Eluting Stent (ELUTES) trial. Circulation 2004;109:487-93.

18. Ardissino D, Cavallini C, Bramucci E, et al. Sirolimus-eluting vs uncoated stents for prevention of restenosis in small coronary arteries: a randomized trial. JAMA 2004;292:2727-34

19. Stone GW, Ellis SG, Cox DA, et al. A polymer-based, paclitaxel-eluting stent in patients with coronary artery disease. $N$ Engl J Med 2004;350:221-31.

20. Kimura T, Yokoi H, Nakagawa Y, et al. Three-year follow-up after implantation of metallic coronary-artery stents. N Engl J Med 1996;334:561-6.

21. Williams DO, Abbott JD, Kip KE. Outcomes of 6906 patients undergoing percutaneous coronary intervention in the era of drug-eluting stents: report of the DEScover Registry. Circulation 2006;114:2154-62.

22. Jensen LO, Maeng M, Kaltoft A, et al. Stent thrombosis, myocardial infarction, and death after drug-eluting and bare-metal stent coronary interventions. J Am Coll Cardiol 2007;50:463-70.

23. Lagerqvist B, James SK, Stenestrand U, et al. Long-term outcomes with drugeluting stents versus bare-metal stents in Sweden. N Engl J Med 2007;356:100919. Epub 2007 Feb 12

24. Tu JV, Bowen J, Chiu M, et al. Effectiveness and safety of drug-eluting stents in Ontario. N Engl J Med 2007;357:1393-402.

25. Ong AT, van Domburg RT, Aoki J, et al. Sirolimus-eluting stents remain superior to bare-metal stents at two years: medium-term results from the Rapamycin-Eluting Stent Evaluated at Rotterdam Cardiology Hospital (RESEARCH) registry. $J$ Am Coll Cardiol 2006; 47:1356-60.

26. Mauri L, Silbaugh TS, Garg P, et al. Drug-eluting or bare-metal stents for acute myocardial infarction. N Engl J Med 2008;359:1330-42.

27. Bavry AA, Kumbhani DJ, Helton TJ, et al. Late thrombosis of drug-eluting stents: a meta-analysis of randomized clinical trials. Am J Med 2006;119:1056-61.

28. Ghali WA, Knudtson ML; APPROACH Investigators. Overview of "APPROACH": the Alberta provincial project for outcome assessment in coronary heart disease. Can J Cardiol 2000;16:1225-30.

29. Norris CM, Ghali WA, Knudtson ML, et al. Dealing with missing data in observational health care outcome analysis. J Clin Epidemiol 2000;53:377-83.

30. Southern DA, Norris CM, Quan $\mathrm{H}$, et al. An administrative data merging solution for dealing with missing data in a clinical registry: adaptation from ICD-9 to ICD10. BMC Med Res Methodol 2008;8:1.

31. Graham MM, Faris PD, Ghali WA, et al.; APPROACH Investigators (Alberta Provincial Project for Outcome Assessment in Coronary Heart Disease). Validation of three myocardial jeopardy scores in a population-based cardiac catheterization cohort. Am Heart J 2001;142:254-61.

32. Fleming TR, Harrington DP. Counting processes and survival analysis. New York (NY): John Wiley \& Sons; 1991.

33. Hastie TJ, Tibshirani RJ. Generalized additive models. New York (NY): Chapman \& Hall; 1990 .

34. Holmes DR Jr, Leon MB, Moses JW, et al. Analysis of 1-year clinical outcomes in the SIRIUS trial: a randomized trial of a sirolimus-eluting stent versus a standard stent in patients at high risk for coronary restenosis. Circulation 2004;109:634-40.

35. Marzocchi A, Saia F, Piovaccari G, et al. Long-term safety and efficacy of drugeluting stents: two-year results of the REAL (REgistro AngiopLastiche dell'Emilia Romagna) multicenter registry. Circulation 2007;115:3181-8.

36. Spaulding C, Henry P, Teiger E, et al. Sirolimus-eluting versus uncoated stents in acute myocardial infarction. N Engl J Med 2006;355:1093-104.

37. Laarman GJ, Suttorp MJ, Dirksen MT, et al. Paclitaxel-eluting versus uncoated stents in primary percutaneous coronary intervention. N Engl J Med 2006;355:1105-13.

38. Pfisterer M, Brunner-La Rocca HP, Buser PT, et al. Late clinical events after clopidogrel discontinuation may limit the benefit of drug-eluting stents: an observationa study of drug-eluting versus bare-metal stents. J Am Coll Cardiol 2006;48:2584-91.

39. Daemen J, Serruys PW. Drug-eluting stent update 2007: part II: unsettled issues. Circulation 2007;116:961-8.

Correspondence to: Dr. William A. Ghali, Departments of Medicine and Community Health Sciences, University of Calgary 3330 Hospital Dr. NW, Calgary AB T2N 4N1; fax 403 210-3818; wghali@ucalgary.ca

\section{APPROACH Clinical Steering Committee \\ Edmonton: Drs. Ross Tsuyuki (chair), Wayne Tymchak, Michelle Graham, Arvind Koshal and Neil Brass \\ Calgary: Drs. Michael Curtis, William A. Ghali, Merril L. Knudtson, Andrew Maitland, L. Brent Mitchell and Mouhieddin Traboulsi}

